\title{
Differing phagocytic function of monocytes and neutrophils in Chagas' cardiopathy according to the presence or absence of congestive heart failure
}

\author{
Diferenciada função de monócitos e neutrófilos na cardiopatia chagásica segundo \\ a presença ou ausência de insuficiência cardíaca congestiva
}

\author{
Maria Imaculada Muniz-Junqueira', Lícia Maria Mota ${ }^{1}$, Rodrigo Barbosa Aires ${ }^{1}$ \\ and Luiz Fernando Junqueira Júnior ${ }^{2}$
}

\begin{abstract}
We evaluated the in vitro phagocytic function and the production of microbicidal oxygen radicals by monocytes and neutrophils of 9 Chagas' heart disease subjects with heart failure and 9 without the syndrome in comparison with 11 healthy subjects, by assessing phagocytosis of Saccharomyces cerevisiae and NBT reduction by peripheral blood phagocytes. Phagocytic index of monocytes of chagasics without heart failure was significantly 6.7 and 10.6 times lower than those of controls and chagasics with the congestive syndrome, respectively, due to a lesser engagement in phagocytosis and to an inability of these cells to ingest particles. Neutrophils also show in chagasics without heart failure PI 11.2 and 19.8 times lower than that of controls and chagasics with heart failure, respectively. The percent of NBT reduction was normal and similar for the three groups. Balanced opposite effects of cardiovascular and immune disturbances may be acting in Chagas' disease subjects with heart failure paradoxically recovering the altered phagocytic function.
\end{abstract}

Key-words: Chagas' heart disease. Cardiac failure. Phagocytosis. Nitro blue tetrazolium test. Neutrophils. Monocytes.

\section{RESUMO}

A função fagocitária e a produção de radicais microbicidas de oxigênio pelos monócitos e neutrófilos foram avaliadas em 9 pacientes com cardiopatia chagásica com insuficiência cardíaca congestiva e 9 sem a síndrome em comparação com 11 indivíduos controles normais pelo teste de fagocitose de Saccharomyces cerevisiae e redução do nitroblue tetrazolium pelos fagócitos do sangue periférico. 0 índice fagocitário dos monócitos dos chagásicos sem insuficiência cardíaca foi significantemente 6,7 e 10,6 vezes menor do que o dos controles e chagásicos com a síndrome congestiva, respectivamente, devido ao menor envolvimento na fagocitose e a menor capacidade destas células de ingerirem partículas. Nos chagásicos sem insuficiência cardíaca os neutrófilos também apresentaram o IF11,2 e 19,8 vezes menor que os controles e chagásicos com insuficiência cardíaca, respectivamente. A porcentagem de redução do NBT foi normal e similar para os três grupos. Efeitos opostos equilibrados das disfunções devidas às alterações cardiovasculares e imunes podem ter atuado nos pacientes chagásicos com insuficiência cardíaca paradoxalmente recuperando a função fagocitária alterada.

Palavras-chaves: Cardiopatia chagásica. Insuficiência cardíaca. Fagocitose. Teste do nitro blue tetrazolium. Neutrófilos. Monócitos.

Chagas' disease is a lifelong endemic infectious condition caused by the intracellular hemoflagellate parasite Trypanosoma cruzi that affects mainly the heart and digestive tract causing an acute local inflammatory reaction which may be followed by a long-lasting progressive chronic cellular and humoral immune process resulting in variable lesion with functional impairment mainly of the common and specialized myocardial cells, myoenteric fibers, peripheral intrinsic autonomic ganglia and nerve fibers, and muscarinic and beta-adrenergic cell receptors 2122643446 . Pathogenesis of progressive chronic cardiac lesions is a matter

1. Laboratório de Imunologia Celular da Faculdade de Medicina da Universidade de Brasília, Brasília, DF. 2. Serviço de Cardiologia do Hospital Universitário de Brasília da Universidade de Brasília, Brasília, DF.

Address to: Dra. Maria Imaculada Muniz-Junqueira. Laboratório de Imunologia Celular, Faculdade de Medicina, Universidade de Brasília, 70910-900 Brasília, DF, Brasil. Fax: 5561 273-3907

e-mail: mimjunqueira@unb.br

Recebido para pulicação em 28/11/2003

Aceito em 27/9/2004 
of controversy, with some evidence suggesting a long-lasting autoimmune reaction triggered in the acute phase, whereas other authors have pointed to a continuous immune stimulus mechanism requiring parasite persistence during the chronic phase $\mathrm{p}^{12434} 47$.

Chagas' disease in its chronic stage is a major challenge for public health in South and Central America countries, where it affects about 16 to 18 million people under different clinical forms, denominated indeterminate, exclusive cardiac or digestive and combined cardiac plus digestive ${ }^{52}$. It presents high morbidity and mortality principally due to a peculiar chronic cardiopathy that occurs in about $30-40 \%$ of infected individuals, which commonly results in congestive heart failure of variable severity, constituting the main cause of disability and death ${ }^{20}{ }^{42}{ }^{44}$.

Congestive heart failure is a complex functional disturbance that implicates a multiplicity of inter-playing hemodynamic, autonomic nervous, metabolic, hormonal, hydro-electrolytic and immunological mechanisms and factors among others ${ }^{17} 1930$. Cytokines, especially the pro-inflammatory ones, tumor necrosis factor- $\alpha$, and IL- 1 and IL- 6 are some of the immunological factors produced by immune cells ${ }^{716}$ involved in the syndrome of heart failure ${ }^{12730}$. Tumor necrosis factor- $\alpha$, a product of activated macrophages, is increased in the serum of patients with severe congestive heart failure $e^{48} 51$, and it has been suggested that this cytokine can play an important role in the pathogenesis of this syndrome ${ }^{29} 32$.

On the other hand, tumor necrosis factor- $\alpha$ may decrease or increase the phagocytic capacity of human monocytes depending on the concentration of this cytokine ${ }^{39}$. Other observations indicate that cytokines produced by monocytes and neutrophils may also influence the heart mechanical function ${ }^{232}$. In addition, monocytes and neutrophils are the main cells involved in the defense againstbacteria that may cause infections, which might complicate the clinical course of patients with heart failure ${ }^{18}$. However, it is not yet known if the pathophysiological changes observed in congestive heart failure may alter the function of cells of the immune system.

Increased production of tumor necrosis factor- $\alpha$ in Chagas' disease patients with chronic cardiomyopathy ${ }^{10}$ and in chronic experimental Trypanosoma cruzi infection ${ }^{33}$ has been observed. Altered concentrations of other cytokines produced by monocytes and neutrophils have also been observed in Chagas' heart disease subjects $^{1011}$. In addition, peripheral blood monocytes and heart macrophages play a crucial role in the resistance to development of Chagas' disease ${ }^{2531}$.

Therefore, itmaybe important to investigate the innate immune function represented by the phagocytosis in Chagas' heart disease and its congestive heart failure syndrome to gain insights into the overall pathophysiological mechanisms implicated, including that concerned with conditions such as infectious pictures that may occur in the course of this syndrome. Thus, we aimed to evaluate the still unexplored phagocytic function and the production of microbicidal oxygen radicals by monocytes and neutrophils in Chagas' heartdisease subjects with and without congestive cardiac failure in comparison with healthy control subjects.

\section{MATERIAL AND METHODS}

Study groups. The evaluation included 29 volunteer subjects distributed in three study groups: a) control group of healthy subjects ( $\mathrm{n}=11), 9$ male and 2 female, aged 20 to 45 years (median, 28 years) ; b) Chagas' heart disease without congestive cardiac failure group ( $\mathrm{n}=9), 4$ male and 5 female, aged 17 to 56 years ( median, 40 years) ; c) Chagas' heart disease with NYHA functional class III-IV congestive cardiac failure group $(n=9)$, 8 male and 1 female, aged 16 to 58 years (median, 48 years). The subjects of the groups did not differ statistically in their ages ( $p>0.05$, Kruskal-Wallis test). Possible influencing factors on the immunological function were ruled out in the control subjects and none was using any drug. The chagasic subjects with heart disease included had no other suspected or associated disease. Those with heart failure were taking conventional drug therapy for their heart condition, such as, diuretics (furosemide), vasodilators (prazosin or hydralazine), angiotensin converting enzyme inhibitors ( captopril or enalapril) , aldosterone inhibitors (spironolactone) and antiarrhythmics (amiodarone). Chagas' heart disease patients had no epidemiological, clinical, electrocardiographic and echodopplercadiographic evidence of heart disease due to other etiology.

The diagnostic criteria for exclusive Chagas' heart disease were the presence of specific positive serologic reactions (indirect immunofluorescence) and cardiac clinical manifestations with typical alterations in the electrocardiogram characteristic of the disease ${ }^{20} 2144$. Congestive heart failure was diagnosed on the basis of the clinical and laboratory manifestations of the syndrome. No chagasic patient showed digestive symptoms and all had epidemiological history of exposure to the transmission vector of the disease.

The ethical rules of the Helsinki Declaration and those from the Brazilian National Council of Health for experimentation in human beings were strictly followed throughout this work. The Human Research Ethical Committee of University of Brasilia Faculty of Medicine approved the experimental protocol, and each subject examined signed written informed consent for participation.

Phagocytic test. Phagocytosis of Saccharomyces cerevisiae was adapted from a technique previously described ${ }^{37}$. Briefly, samples of $40 \mathrm{ml}$ per marked area of heparinized whole peripheral blood obtained by means of venopuncture from each subject were placed on clean glass slides containing 8 marked areas of $7 \mathrm{~mm}$ diameter each, in duplicate preparations, and incubated in a wet chamber for $45 \mathrm{~min}$ at $37^{\circ} \mathrm{C}$. The slides were then rinsed with $0.15 \mathrm{M}$ phosphate-buffered saline (PBS) $\mathrm{pH} 7.2$ at $37^{\circ} \mathrm{C}$ to remove non-adherent cells. After washing, neutrophils ${ }^{928}$ and monocytes ${ }^{39}$ remained adhered onto the slide approximately in the same proportion as they were in the whole blood. Adherent cells (12,534 \pm 5,050 cells/marked area; $5.63 \pm$ $0.85 \%$ monocytes and $93.5 \pm 1.08 \%$ neutrophils) were incubated with a suspension of $2.5 \times 10^{5} \mathrm{~S}$. cerevisiae in $20 \mu \mathrm{l}$ Hanks-tris ( Sigma, St Louis, M0, USA) pH 7.2, with 10\% fetal 
calf serum (FCS) (Cultilab, Campinas, Brazil), for $30 \mathrm{~min}$ in a wet chamber at $37^{\circ} \mathrm{C}$, to allow phagocytosis. Slides were then rinsed with $0.15 \mathrm{M}$ PBS at $37^{\circ} \mathrm{C}$ to eliminate nonphagocytosed S. cerevisiae and the final washing was done with $30 \%$ FCS in Hanks-tris. The slides were fixed with absolute methanol and stained with 10\% Giemsa solution. The number of S. cerevisiae phagocytosed by 200 monocytes or by 200 neutrophils in individual preparations was assessed by optical microscopy. Microscopic fields distributed throughout the slide were randomly selected and all monocytes or neutrophils in each particular field were examined. The phagocytic index was calculated as the average number of phagocytosed S. cerevisiae per phagocytosing monocytes or neutrophils, multiplied by the percentage of these cells engaged in the phagocytosis ${ }^{38}$.

Baking yeast ( Saccharomyces cerevisiae) was prepared according to a technique previously described ${ }^{37}$. In short, $50 \mathrm{~g}$ of fresh live yeast (Fleischmann, Brazil) were resuspended in $220 \mathrm{ml}$ of PBS, pH 7.2 , autoclaved at $120^{\circ} \mathrm{C}$ for $30 \mathrm{~min}$, washed in PBS until obtaining a clear supernatant and the sediment was resuspended in $28 \mathrm{ml}$ of a $0.1 \mathrm{M}$ 2-mercaptoethanol solution in PBS. After 2 hours incubation with stirring, yeasts were washed again and resuspended in $55 \mathrm{ml}$ of $0.02 \mathrm{M}$ iodoacetamide in PBS. After an extra 2 hours incubation with stirring at room temperature, they were washed 3 times and resuspended in $220 \mathrm{ml}$ of PBS, pH 7.2. Yeasts were again autoclaved, washed and resuspended in $110 \mathrm{ml}$ of veronal buffered saline, pH 7.2, containing sodium azide, and stored at $4^{\circ} \mathrm{C}$ until use. Before each experiment, dead S. cerevisiae were washed in PBS, quantified and resuspended in Hanks-tris solution.

Nitro blue tetrazolium slide test. Nitro blue tetrazolium (NBT) test was adapted from the technique described by Campbell and Douglas ${ }^{5}$, aiming to evaluate the microbicidal mechanism of phagocytes by their ability to generate toxic oxygen radicals capable of reducing the compound NBT to an insoluble form, named formazan, which is identified under optical microscopy by a blue color in the cytoplasm of the cell. The amount of NBT reduced is directly proportional to the amount of oxygen radicals produced by phagocytes ${ }^{5}$, and these molecules are among the principal microbicidal agents produced by phagocytes ${ }^{49}$. Briefly, phagocytes adhered on slide, as previously described, were incubated with $0.05 \%$ NBT solution in Hanks-tris ( Sigma, St Louis, MO, USA) for $20 \mathrm{~min}$ at $37^{\circ} \mathrm{C}$ in a humidified chamber. The slide were then washed, fixed with methanol and stained with a solution of $1.4 \%$ safranin and $28.6 \%$ glycerol in distillate water. The percent phagocytes with NBT reduced in the cytoplasm was assessed by optical microscopy.

Statistical analysis. The Kruskal-Wallis non-parametric statistic was used to simultaneously compare the three groups for each variable studied. Multiple comparisons were conducted with Dunn's post-hoc test when the Kruskal-Wallis analysis showed an overall significant difference between the groups. The MannWhitney test was performed to compare two independent groups. Differences with a two-tailed value of $p<0.05$ were considered statistically significant. The Prism ${ }^{\circledR}$ software package ( GraphPad, USA, 1997) was utilized for analysis and design of the data.

\section{RESULTS}

No statistically significant difference was found between the median of phagocytic index of neutrophils and monocytes from males and females in both control group and chagasic individuals $(p>0.05)$.

Table 1 shows the comparison of the different functional variables of phagocytosis by monocytes and neutrophils between the groups of Chagas' disease patients with and without congestive heart failure and the healthy control group.

Alterations in the phagocytic function of monocytes and neutrophils observed comparatively between the two groups of patients with Chagas' heart disease and the control group are illustrated in Figure 1. The group of patients with Chagas' heart disease without congestive cardiac failure showed decreased monocyte and neutrophil phagocytic function as compared with normal subjects and chagasic patients with heart failure.

Table 1- Median (extreme values) of the variables of in vitro phagocytic function and microbicidal oxygen radical production capacity evaluated by the nitro blue tetrazolium reduction test of circulating monocytes and neutrophils, observed for control healthy subjects and Chagas' heart disease subjects with and without congestive cardiac failure.

\begin{tabular}{|c|c|c|c|c|c|c|c|}
\hline & \multicolumn{3}{|c|}{ Phagocytosis by monocytes } & \multicolumn{3}{|c|}{ Phagocytosis by neutrophils } & \multirow[b]{2}{*}{$\begin{array}{l}\% \mathrm{NBT} \\
\text { reduction }\end{array}$} \\
\hline & $\begin{array}{c}\text { number of S. cerevisiae } \\
\text { phagocytosed }\end{array}$ & $\begin{array}{l}\% \text { cells engaged } \\
\text { in phagocytosis }\end{array}$ & $\begin{array}{l}\text { phagocytic } \\
\text { index }\end{array}$ & $\begin{array}{c}\text { number of S. cerevisiae } \\
\text { phagocytosed }\end{array}$ & $\begin{array}{l}\text { \% cells engaged } \\
\text { in phagocytosis }\end{array}$ & $\begin{array}{c}\text { phagocytic } \\
\text { index }\end{array}$ & \\
\hline $\begin{array}{l}\text { Control subjects } \\
(\mathrm{n}=11)\end{array}$ & $\begin{array}{c}1.32 \\
(1.00-1.65)\end{array}$ & $\begin{array}{c}23.0 \\
(6.0-50.5)\end{array}$ & $\begin{array}{c}27.0 \\
(6.0-80.5)\end{array}$ & $\begin{array}{c}1.58 \\
(1.12-2.23)\end{array}$ & $\begin{array}{c}19.0 \\
(3.0-68.5)\end{array}$ & $\begin{array}{c}28.0 \\
(3.5-125.0)\end{array}$ & $\begin{array}{c}86.5 \\
(45.5-98.5)\end{array}$ \\
\hline $\begin{array}{l}\text { Chagas' heart disease subjects } \\
\text { without cardiac failure }(n=9)\end{array}$ & $\begin{array}{c}1.12^{b} \\
(1.00-1.41)\end{array}$ & $\begin{array}{c}4.0^{\mathrm{a}, \mathrm{b}} \\
(1.5-16.5)\end{array}$ & $\begin{array}{c}4.0^{\mathrm{a}, \mathrm{b}} \\
(1.5-24.5)\end{array}$ & $\begin{array}{c}1.29 \\
(0-1.91)\end{array}$ & $\begin{array}{c}2.0^{\mathrm{a}, \mathrm{b}} \\
(0-18.5)\end{array}$ & $\begin{array}{c}2.5^{a, b} \\
(0-29.5)\end{array}$ & $\begin{array}{c}81.5 \\
(33.5-92.5)\end{array}$ \\
\hline $\begin{array}{l}\text { Chagas' heart disease subjects } \\
\text { with cardiac failure }(\mathrm{n}=9)\end{array}$ & $\begin{array}{c}1.33 \\
(1.08-1.74)\end{array}$ & $\begin{array}{c}32.5 \\
(2.0-54.0)\end{array}$ & $\begin{array}{c}42.5 \\
(9.0-97.0)\end{array}$ & $\begin{array}{c}1.56 \\
(1.24-2.43)\end{array}$ & $\begin{array}{c}28.0 \\
(2.0-40.0)\end{array}$ & $\begin{array}{c}49.5 \\
(3.0-88.5)\end{array}$ & $\begin{array}{c}74.7 \\
(34.5-94.0)\end{array}$ \\
\hline p value* & 0.03 & 0.02 & 0.006 & 0.17 & 0.003 & 0.003 & 0.40 \\
\hline
\end{tabular}

* Kruskal-Wallis test. Multiple pair wise comparisons were performed by the Dunn's post-test when an overall significant difference was verified between the groups.

a significant difference $(\mathrm{p}<0.05)$ between control and Chagas' heart disease subjects groups by the Dunn's post-test.

${ }^{b}$ significant difference $(p<0.05)$ between Chagas' heart disease subjects groups with and without cardiac failure by he Dunn's post-test. 

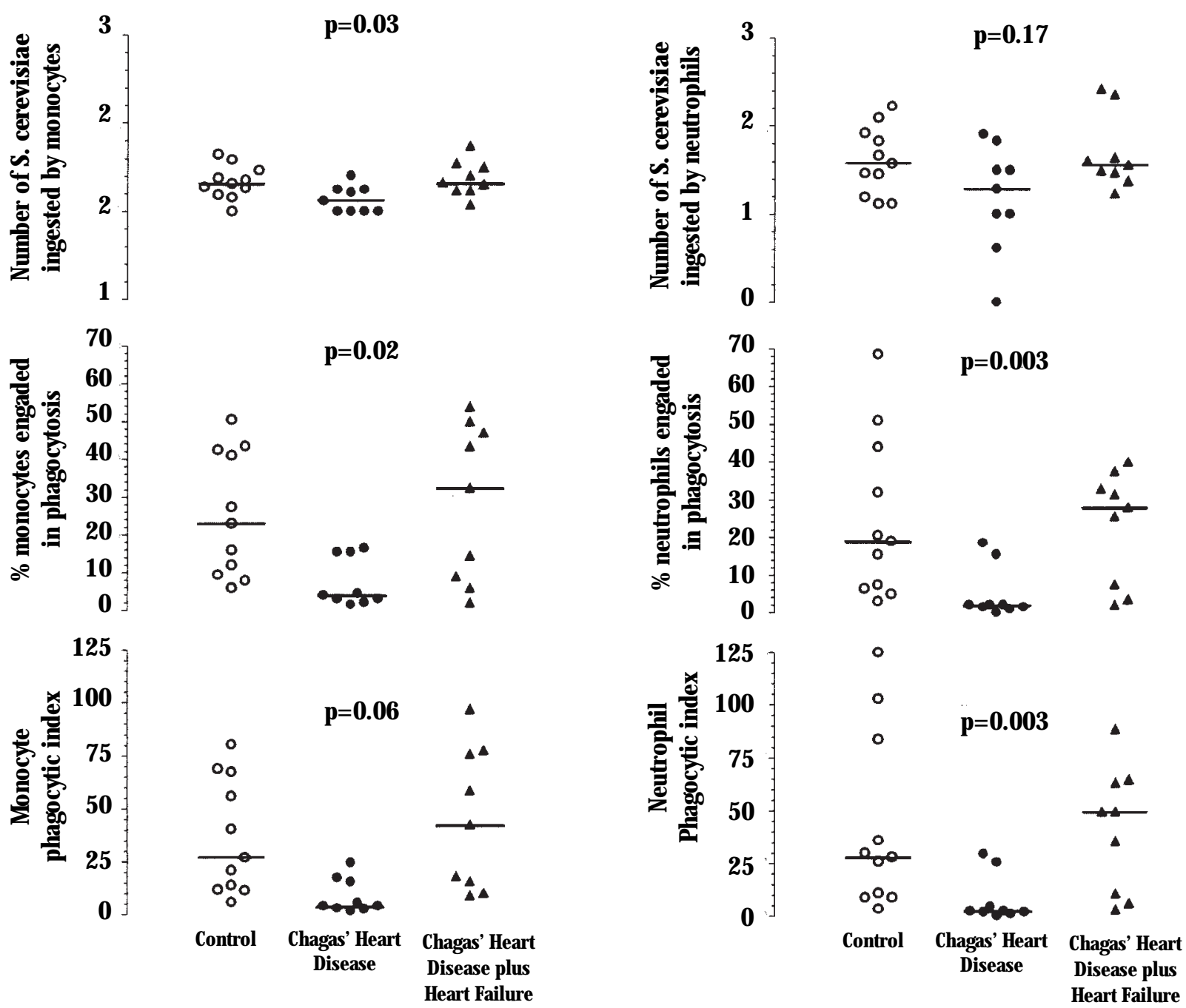

Figure 1 - Comparison of monocyte (left) and neutrophil (right) phagocytic capacity between the groups of Chagas' heart disease patients with $(n=9)$ and without $(n=9)$ cardiac failure and control healthy subjects $(n=11)$. Individual values are shown for the number of Saccharomyces cerevisiae $\left(2.5 \times 10^{5}\right.$ per marked area) phagocytosed by phagocyte (top), proportion of phagocytes engaged in phagocytosis (middle), and the respective phagocytic index (bottom). The horizontal lines represent the median value for each group. The Kruskal-Wallis analysis with Dunn's post-hoc test was used to compare the groups.

The median of phagocytic index of monocytes of Chagas' heart disease patients without heart failure (4) was several times lower (6.7 and 10.6, respectively) ( $p=0.006$, Kruskal-Wallis test) than that of control individuals (27) and chagasics with heart failure (42.5). No statistically significant difference was observed between these two latter groups ( $p>0.05$, Dunn's post-test). The reduced phagocytic index was due to reduction in the number of phagocytosed Saccharomyces cerevisiae and reduction in the number of monocytes engaged in phagocytosis. Similarly, median of phagocytic index of neutrophils of Chagas' heart disease patients without heart failure was also reduced (2.5) ( $p=0.003$, Kruskal-Wallis test) in comparison with normal (28) and chagasic with heartfailure subjects (49.5). This reduction was mainly due to lower quantitative involvement of neutrophils in phagocytosis. Likewise, no statistical difference was noted between the Chagas' disease with heart failure and control groups ( $p>0.05$, Dunn's post test).

Patients with Chagas' heart disease and heart failure showed no statistically significant differences in the variables of phagocytic function of monocytes and neutrophils when compared with control healthy subjects.

The capacity to generate toxic oxygen radicals evaluated by the percentreduction of NBT was notinfluenced by the presence or absence of heart failure in Chagas' heart disease subjects, and no differences were observed between the three groups, as indicated in Table 1 and illustrated in Figure 2.

\section{DISCUSSION}

The present study showed that Chagas' heart disease patients without congestive cardiac failure presented reduced phagocytic capacity of monocytes and neutrophils. On the other hand, patients with heart failure showed phagocytic function of these immune cells similar to healthy subjects, suggesting that the depressed immune function of monocytes and neutrophils was reversed in the presence of the heart failure syndrome. These 


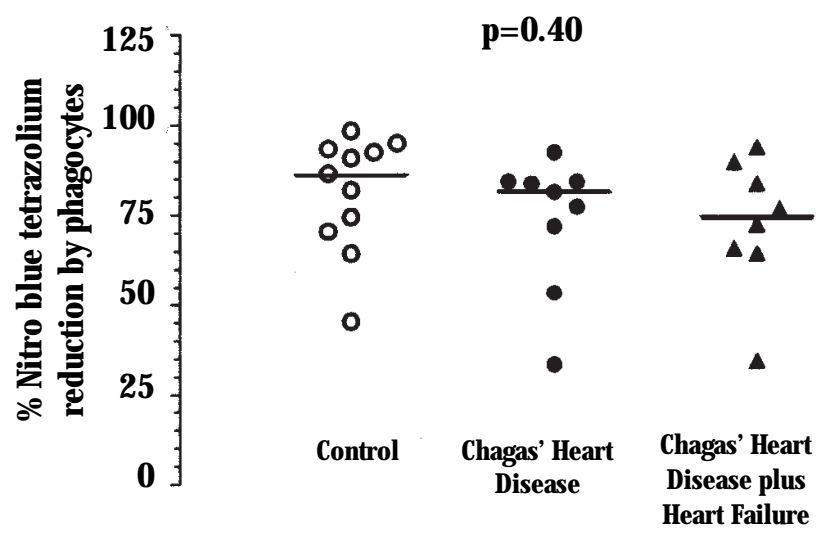

Figure 2 - Comparison of phagocyte production of microbicidal oxygen radical molecules assessed as percent reduction of nitro blue tetrazolium between the groups of Chagas' heart disease patients with $(\mathrm{n}=9)$ and without $(\mathrm{n}=9)$ cardiac failure and control healthy subjects $(n=11)$. Individual values are shown for the percent nitro blue tetrazolium (NBT) reduction. The horizontal lines represent the median value for each group. The Kruskal-Wallis analysis with Dunn's post-hoc test was used to compare the groups.

data suggest that the association of heart failure syndrome with chronic Trypanosoma cruzi infection appears to cause an activation of the depressed phagocytes in Chagas' heart disease patients noted in the absence of cardiac failure.

An enhanced activity of mononuclear phagocyte cells has been demonstrated during acute Trypanosoma cruzi infection in experimental animals ${ }^{683141}$, which was dependent on the parasite strain inoculated in the animals evaluated ${ }^{8}$. On the contrary, we observed a decreased phagocytic function during chronic cardiac T. cruzi infection withoutheartfailure. Reduction of chemotaxis of blood monocytes and neutrophils and a tendency for depressed nitro blue tetrazolium reduction by phagocytes has also been observed in patients with chronic Chagas' disease without heart failure ${ }^{13} 50$.

The reasons why there were no alterations in phagocytic function of monocytes and neutrophils in patients with heart failure associated with chronic Chagas' heart disease are not clear. However, a possible hypothesis to explain our results is that it was due to an increased production of cytokines capable of influencing phagocyte functions when heart failure is present in patients with Chagas' disease. In fact, altered cytokine production has been demonstrated in patients with Chagas' disease ${ }^{11}$ and in patients with heart failure syndrome of other cause $^{230}{ }^{33}$. The coexistence of heart failure and Trypanosoma cruzi infection in the patients presently evaluated may have altered the cytokine secretion and influenced phagocytosis. This may occur because the type of influence of cytokines on phagocytosis may depend on cytokine concentration. In fact, as we previously observed, TNF- $\alpha$ may increase or decrease the phagocytic function of monocytes depending on its concentration $^{39}$. In the complex syndrome of heart failure associated with Trypanosoma cruzi infection there are many factors influencing the final function of each cell. It has been shown that antigens of Trypanosoma cruzi may induce the production of pro-inflammatory cytokines ${ }^{4}$, and immune and inflammatory cytokines may be increased in serum of chagasic patients ${ }^{11}$. Plasma concentration of inflammatory cytokines seems to be increased in patients with heart failure of any etiology, and correlates with the severity of symptoms ${ }^{1729}$. On the other hand, heartfailure is associated with hemodynamic, hydro-electrolytic, hormonal and autonomic neural disturbances and may also modify the cytokine production. Thus, it can be conjectured that the interplay between these functional alterations resulting in counterbalanced opposite immune effects is the probable cause for the paradoxically normalized phagocytic capacity of phagocytes observed in Chagas' heart disease patients with congestive heartfailure, although the phagocytic function of these immune cells is actually deficient per se.

An alternative hypothesis to explain the differing phagocytic function observed would be a different deregulation of $\mathrm{T}$ cell regulatory secreting IL-10 or TGF- $\beta$ in patients with Chagas' disease in presence or absence of heart failure ${ }^{35}$.

It should be also considered the possibility of the influence on phagocytosis by neutrophils and monocytes of some drugs in use by the patients with heart failure. However, it seems that this was not the case in the present study, since it has been shown that furosemide and spironolactone does not alter phagocytosis ${ }^{23}{ }^{36}$, and captopril, enalapril, amiodarone or hydralazine may decrease phagocyte functions ${ }^{141} 1545$ causing an opposite effect of that observed in the patients with heart failure presently studied.

The capacity to reduce NBT to formazan indicates that the phagocytes are producing oxygen radicals, which are important microbicidal mechanism of these cells causing pathogen death ${ }^{549}$. Unlike the observation of decreased phagocytic capacity of monocytes and neutrophils in Chagas' heart disease patients without heart failure, we were unable to detect any alteration in percent reduction of NBT. This fact suggests that the destruction of pathogens after ingestion by phagocytes was not compromised in the patients examined with or without heart failure. On the contrary to the present findings, Voltarelli et $\mathrm{al}^{50}$ observed a tendency for diminished percent of NBT reduction in chagasic patients with cardiac disease withoutheart failure or with digestive form of the disease. These results apparently conflict with ours, and may be related to different clinical aspects or stages of evolution of Chagas' cardiopathy in the subjects in each study.

Many unfavorable consequences, such as predisposition to infections or direct mechanical heart dysfunction, can result from partially inadequate function of phagocytes in chagasic patients, considering that these immune cells play multiple roles in resistance mediated by the immune system against Trypanosoma cruzi ${ }^{25}{ }^{31}$. It should be stressed that the normalized phagocytic function noted in Chagas' heart disease associated with cardiac failure seems to be a secondary phenomenon occurring possibly as a balanced effect in consequence of increased levels of cytokines encountered in non-specific heart failure ${ }^{20}$, which stimulate the phagocytes. Neutrophils and monocytes are also involved in firstline defense against infections by extra-cellular bacteria ${ }^{18}$, and patients with heart failure may present different infections that threaten their lives, as a complication caused by bacteria that depend on normal phagocytes function for their elimination ${ }^{3}$, suggesting dysfunction of these cells. 
One possible limitation of the present study concerns the extrapolation of an in vitro laboratory finding for a clinical condition that involves a multiplicity of interplaying functional factors. In this respect, it should be pointed out that there is no alternative means to that utilized here to demonstrate the effects of different factors acting directly on phagocytic cells. It is obvious that the definitive proof of the in vivo relationship between the phagocytic function of monocytes and neutrophils and the occurrence or predisposition or not to infections in patients with or without heart failure requires a prospectively designed longitudinal clinical study.

We believe that our study underscores the complex pathophysiological interplay between Chagas' heart disease, the consequent heart failure syndrome and phagocyte functions, showing that the immune system may be differently compromised in both clinical conditions according to the heart functional status, which suggests that the disturbances proper to each condition per se appear to affect one another. In the clinical setting, the resulting immune alterations of these interplaying pathophysiological mechanisms may influence the clinical evolution and the outcome of the affected patients.

In conclusion, our data showed that phagocytic function of monocytes and neutrophils was considerably decreased in chronic Chagas' cardiopathy in the absence of heartfailure, while this function was observed to be normal in the presence of the congestive syndrome. This fact suggests that balanced opposite effects on the phagocytosis, consequent to cardiovascular and immune disturbances, may be acting in Chagas' congestive heart failure and paradoxically normalizing the phagocytic function. The altered phagocytic function of Chagas' disease patients should be taken into consideration when it is necessary to prescribe drug therapy, such as for example antibiotics, that may also influence phagocyte functions, in order to avoid aggravation of these deficiencies.

\section{ACKNOWLEDGEMENTS}

The authors gratefully thank Mrs. Renê Oliveira Pires and Mr. José Siqueira for technical assistance. Dr. Lícia Maria Mota and Dr. Rodrigo Barbosa Aires were fellowship recipients supported by PIBIC-UnB/CNPq at the Laboratory of Cellular Immunology.

\section{REFERENCES}

1. Agoston I, Dibbs ZI, Wang F, Muller G, Zeldis JB, Mann DL, Bozkurt B. Preclinical and clinical assessment of the safety and potential efficacy of thalidomide in heart failure. Journal of Cardiac Failure 8: 306-313, 2002.

2. Blum A, Miller H. Pathophysiological role of cytokines in congestive heart failure. Annual Review of Medicine 52: 15-27, 2001.

3. Braunwald E, Grossman W, Clinical aspects of heart failure. In: Braunwald E (ed) Heart Disease: a textbook of cardiovascular medicine, $4^{\text {th }}$ edition, Saunders, Philadelphia, p. 444-463, 1992.

4. Camargo MM, Almeida IC, Pereira MES, Ferguson MAJ, Travassos LR, Gazzinelli RT. Glycosylphosphatidylinositol-anchored mucin-like glycoproteins isolated from Trypanosoma cruzi trypomastigotes initiate the synthesis of proinflammatory cytokines by macrophages. The Journal of Immunology 158: 5890-5901, 1997.
5. Campbell DE, Douglas SD. Phagocytic cell functions. I. Oxidation and chemotaxis. In: Rose NR, de Macario EC, Folds JD, Lane HC, Nakamura RM ( eds) Manual of Clinical Laboratory Immunology, $5^{\text {th }}$ edition American Society for Microbiology, Washington, p. 320-328, 1997.

6. Cardoni RL, Rottenberg ME, Segura EL. Increased production of reactive oxygen species by cells from mice acutely infected with Trypanosoma cruzi. Cellular Immunology 128: 11-21, 1990.

7. Cassatella MA, Gasperini S, Russo MP. Cytokine expression and release by neutrophils. Annals of the New York Academy of Sciences 832: 233-242, 1997.

8. Celentano AM, Cappa SMG. In vivo macrophage function in experimental infection with Trypanosoma cruzi subpopulations. Acta Tropica 55: 171180, 1993.

9. Chen T, Gotschlich EC. CGM1a antigen of neutrophils, a receptor of gonococcal opacity proteins. Proceedings of the National Academy of Sciences 93: 14851-14856, 1996.

10. Cunha-Neto E, Rizzo LV, Albuquerque F, Abel L, Guilherme L, Bocchi E, Bacal F, Carrara D, Ianni B, Mady C, Kalil J. Cytokine production profile of heart-infiltrating $\mathrm{T}$ cells in Chagas' disease cardiomyopathy. Brazilian Journal of Medical and Biological Research 31: 133-137, 1998.

11. Dutra WO, Gollob KJ, Pinto-Dias JC, Gazzinelli G, Correa-Oliveira R, Coffman RL, Carvalho-Parra JF. Cytokine mRNA profile of peripheral blood mononuclear cells isolated from individuals with Trypanosoma cruzi chronic infection. Scandinavian Journal of Immunology 45: 74-80, 1997.

12. Engman DM, Leon JS. Pathogenesis of Chagas heart disease: role of autoimmunity. Acta Tropica 81: 123-132, 2002.

13. Ferreira GG, Argueles E, Oliveira-Lima AL. Depression of blood monocytes chemotaxis in human chronic Chagas disease. Revista do Instituto de Medicina Tropical de São Paulo 21: 297-301, 1979.

14. Freischlag JA, Colburn MD, Quinones-Baldrich WJ, Moore WS. Alteration of neutrophil (PMN) function by heparin, dexamethasone, and enalapril. Journal of Surgery Research 52: 523-529, 1992.

15. Futamura Y. Amiodarone induces two different types of disorders in mouse alveolar macrophages. Japanese Journal of Pharmacology 74: 21-28, 1997.

16. Georgiev VS, Albright JF. Cytokines and their role as growth factors and in regulation of immune responses. Annals of the New York Academy of Sciences 685: 584-602, 1993.

17. Givertz MM, Colucci WS. New targets for heart-failure therapy: endothelin, inflammatory cytokines, and oxidative stress. The Lancet 352 ( suppl I): 34-38, 1998.

18. Gotschlich EC. Immunity to extracellular bacteria. In: Paul WE( ed) Fundamental Immunology, 3rd edition, New York: Raven Press, p. 1287-1308, 1993.

19. Jackson G, Gibbs CR, Davies MK, Lip GYH. ABC of heart failure. Pathophysiology. British Medical Journal 320: 167-170, 2000.

20. Junqueira Jr LF. Cardiac involvement in Chagas' disease. In: Proceedings: Symposium on Cardiology in a Tropical Environment, South African Medical Research Council, Durban, p. 268-274, 1982.

21. Junqueira Jr LF. Ambulatory assessment of cardiac autonomic function in Chagas' heart disease patients based on indexes of R-R interval variation in the Valsalva maneuver. Brazilian Journal of Medical and Biological Research 23: 1091-1102, 1990.

22. Junqueira Jr LF, Beraldo PSS, Chapadeiro E, Jesus PC. Cardiac autonomic dysfunction and neuroganglionitis in a rat model of chronic Chagas' disease. Cardiovascular Research 26: 324-329, 1992.

23. Kay J, Czop JK. Enhancement of human monocyte beta-glucan receptors by glucocorticoids. Immunology 81: 96-102, 1994.

24. Kierszenbaum F. Chagas' disease and the autoimmunity hypothesis. Clinical Microbiology Reviews 12: 210-223, 1999.

25. Kierszenbaum F, Knecht E, Budzko DB, Pizzimenti M. Phagocytosis: a defense mechanism against infection with Trypanosoma cruzi. The Journal of Immunology 112: 1839-1844, 1974.

26. Köberle F. Chagas' disease and Chagas' syndromes: the pathology of American trypanosomiasis. Advances in Parasitology 6: 63-116, 1968.

27. Krum H. Tumor necrosis factor- $\alpha$ blockade as a therapeutic strategy in heart failure ( RENEWAL and ATTACH) : unsuccessful, to be specific. Journal of Cardiac Failure 8: 365-368, 2002. 
28. Mancuso P, Nana-Sinkam P, Peters-Golden M. Leukotriene $B_{4}$ augments neutrophil phagocytosis of Kebsiella pneumoniae. Infection and Immunity 69: 2011-2016, 2001.

29. Mann DL. Recent insights into the role of tumor necrosis factor in the failing heart. Heart Failure Reviews 6: 71-80, 2001.

30. Mann DL, Deswal A, Bozkurt B, Torre-Amione G. New therapeutics for chronic heart failure. Annual Review of Medicine 53: 59-74, 2002.

31. Melo RC, Machado CR. Trypanosoma cruzi: peripheral blood monocytes and heart macrophages in the resistance to acute experimental infection in rats. Experimental Parasitology 97: 15-23, 2001.

32. Miller WL, BurnettJr JC. Circulating paracrine and autocrine mechanisms in heart failure. Current Opinion in Cardiology 8: 376-382, 1993.

33. Morato MJF, Colley DG, Powell MR. Cytokine profiles during experimental Chagas' disease. Brazilian Journal of Medical and Biological Research 31: 123-125, 1998.

34. Morris SA, Tanowitz HB, Wittner M, Bilezikian JP. Pathophysiological insights into the cardiomyopathy of Chagas' disease. Circulation 82: 19001909, 1990.

35. Mills KHG, McGuirk P. Antigen-specific regulatory T-cells- their induction and role in infection. Seminars in Immunology 16: 107-117; 2004.

36. Muniz-Junqueira MI, Mota LM, Aires RB, Junqueira Jr LF. Digitalis inhibit and furosemide does not change the in vitro phagocytic function of neutrophils of healthy subjects. International Immunopharmacology 3: 1439-1445, 2003

37. Muniz-Junqueira MI, Peçanha LMF, Silva-Filho VL, Cardoso MCA, Tosta CE. Novel microtechnique for assessment of postnatal maturation of the phagocytic function of neutrophils and monocytes. Clinical and Diagnostic Laboratory Immunology 10: 1096-1102, 2003.

38. Muniz-Junqueira MI, Prata A, Tosta CE. Phagocytic and bactericidal function of mouse macrophages to Salmonella typhimurium in schistosomiasis mansoni. The American Journal of Tropical Medicine and Hygiene 46: 132136, 1992.

39. Muniz-Junqueira MI, Santos-Neto LL, Tosta CE. Influence of tumor necrosis factor- $\alpha$ on the ability of monocytes and lymphocytes to destroy intraerythrocytic Plasmodium falciparum in vitro. Cellular Immunology 208: 73-79, 2001.

40. Nagy AM, Vanderbist F, Parij N, Maes P, Fondu P, Neve J. Effect of the mucoactive drug nacystelyn on the respiratory burst of human blood polymorphonuclear neutrophils. Pulmonary Pharmacological Therapy 10: 287-292, 1997.

41. Ortiz-Ortiz L, Ortega T, Capin R, Martinez T. Enhanced mononuclear phagocytic activity during Trypanosoma cruzi infection in mice. International Archives of Allergy Applied Immunology 50: 232-242, 1976.

42. Prata A. Chagas' disease. Infectious Diseases Clinics of North America 8: 61-76, 1994.

43. Prata A. Clinical and epidemiological aspects of Chagas disease. Lancet Infectious Disease 1: 92-100, 2001.

44. Rassi A Jr, Rassi A, Little WC. Chagas' heart disease. Clinical Cardiology 23: 883-889, 2000.

45. Schopf RE, Hanauske-Abel HM, Tschank G, Schulte-Wissermann H, Gunzler V. Effects of hydrazil group containing drugs on leukocyte functions: an immunoregulatory model for the hydralazine-induced lupus-like syndrome. Journal of Immunopharmacology 7: 385-401, 1985.

46. Sterin-Borda L, Borda E. Role of neurotransmitter autoantibodies in the pathogenesis of chagasic peripheral dysautonomia. Annals of the New York Academy of Sciences 917: 273-280, 2000.

47. Tarleton RL. Parasite persistence on the aetiology of Chagas' disease. International Journal for Parasitology 31: 550-554, 2001.

48. Torre-Amione G, Kapadia S, Lee J, Durand JB , Bies RD, Young JB, Mann DL. Tumor necrosis factor- $\alpha$ and tumor necrosis factor receptors in the failing human heart. Circulation 93: 704-711, 1996.

49. Underhill DM, Ozinsky A. Phagocytosis of microbes: complexity in action, Annual Review of Immunology 20: 825-852, 2002.

50. Voltarelli JC, Donadi EA, Carvalho IF, Falcão RP. Lymphocyte subpopulations and neutrophil function in chronic human Chagas' disease. Revista do Instituto de Medicina Tropical de São Paulo 32: 240-248, 1990.

51. Wiedermann CJ, Beimpold H, Herold M, Knapp E, Braunsteiner H. Increased levels of serum neopterin and decreased production of neutrophil superoxide anions in chronic heart failure with elevated levels of tumor necrosis factor- $\alpha$. Journal of the American College of Cardiology 22: 1897-1901, 1993

52. World Health Organization. Control of Chagas' disease. WHO Technical Reports Series 811: 1-95, 1991. 53. Yamaoka-Tojo M, Tojo T, Inomata T, Machida Y, Osada K, Izumi T. Circulating levels of interleukin-18 reflect tetiologies of heart failure: Th1/Th2 cytokine imbalance exaggerates the pathophysiology of advanced heart failure. Journal of Cardiac Failure 8: 21-27, 2002. 